\title{
EDUCAÇÃO PERMANENTE PARA OS AGENTES COMUNITÁRIOS DE SAÚDE: ESTRATÉGIA NO PROCESSO DE TRABALHO
}

Permanent education for community health agents: Strategy in the work process

Educación permanente para agentes de salud comunitarios: estrategia em el processo de trabajo

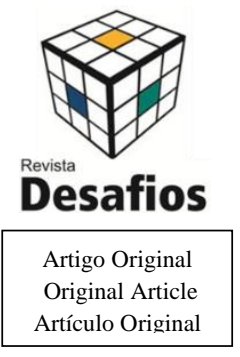

Ana Beatriz Gouveia de Araújo ${ }^{* 1}$, Camila Mendes da Silva², Antônio Ialy Ferreira ${ }^{3}$, Gisetti Corina Gomes Brandão ${ }^{4}$

${ }^{1}$ Graduada em Enfermagem pela Universidade Federal de Campina Grande, Paraíba, Brasil.

${ }^{2}$ Especialista. Mestranda pelo Programa de Pós-graduação em Gerenciamento em Enfermagem pela Escola de Enfermagem da Universidade de São Paulo, São Paulo, Brasil.

${ }^{3}$ Graduado em Enfermagem pela Universidade Federal de Campina Grande, Paraíba, Brasil.

${ }^{4}$ Enfermeira. Professora da Universidade Federal de Campina Grande, Doutora em Ciências pela Universidade de São Paulo, Paraíba, Brasil.

*Correspondência: bia_araujo38@hotmail.com

\section{Artigo recebido em 06/05/2020 aprovado em 15/04/2021 publicado em 22/10/2021.}

\section{RESUMO}

O processo de trabalho do agente comunitário de saúde se relaciona com a nova concepção do modelo de atenção à saúde, dispondo do olhar ampliado sobre o indivíduo, a família e a comunidade na perspectiva biopsicossocial. Com isso, o presente estudo tem por objetivo discutir o processo de trabalho dos agentes comunitários à luz da educação permanente em saúde. Trata-se de uma pesquisa descritiva e exploratória, abordagem qualitativa, delineada pelo constructo da pesquisa-ação. O cenário do estudo foram três unidades de saúde da cidade de Campina Grande-Paraíba. A amostra foi composta por 16 agentes comunitários e a coleta de dados ocorreu através de um questionário estruturado e 32 oficinas de trabalho gravadas, que foram analisados por meio da Técnica de Análise de Conteúdo proposta por Bardin. Três categorias de análise foram evidenciadas: Fragilidades e dificuldades no dia a dia de trabalho, as potencialidades do processo de trabalho do agente comunitário de saúde e perspectivas dos agentes com a educação permanente em saúde. As práticas pedagógicas devem ser baseadas na aprendizagem significativa, para que haja a responsabilização dos sujeitos frente ao seu processo de trabalho e a reflexão crítica sobre o seu dia a dia de trabalho.

Palavras-chave: Trabalho, Atenção Primária à Saúde, Educação Permanente.

\section{ABSTRACT}

The work process of the community health worker is related to the new conception of the health care model, having a broader view of the individual, the family and the community in the biopsychosocial perspective. Thus, the present study aims to discuss the work process of community agents in the light of permanent health education. It is a descriptive and exploratory research with qualitative approach, outlined by the action research construct. The study scenario was three health units in the city of Campina Grande-Paraíba. The sample consisted of 16 community agents and the data collection took place through a structured questionnaire and 32 recorded workshops, which were analyzed using the Content Analysis Technique proposed by Bardin. Three categories of analysis were highlighted: weaknesses and difficulties in the day-to-day work, the potentialities of the community health workers' work process and the perspectives of agents with permanent health education. Pedagogical 
practices must be based on meaningful learning, so that subjects are held accountable to their work process and critical reflection on their daily work.

Keywords: Work, Primary Health Care, Education, Continuing.

\section{RESUMEN}

Proceso de trabajo del agente de salud de la comunidad está relacionado con la nueva concepción del modelo de atención de salud, teniendo una visión más amplia del individuo, la familia y la comunidad en la perspectiva biopsicosocial. Por lo tanto, el presente estudio tiene como objetivo discutir el proceso de trabajo de los agentes de la comunidad a la luz de la educación permanente en salud. Es una investigación descriptiva y exploratoria, un enfoque cualitativo, delineado por el constructo de investigación de acción. El escenario del estudio fue tres unidades de salud en la ciudad de Campina Grande-Paraíba. La muestra consistió en 16 agentes comunitarios y la recolección de datos se realizó a través de un cuestionario estructurado y 32 talleres grabados, que fueron analizados utilizando la Técnica de Análisis de Contenido propuesta por Bardin. Se destacaron tres categorías de análisis: debilidades y dificultades en el trabajo diario, las potencialidades del proceso de trabajo del agente comunitario de salud y las perspectivas de los agentes con educación permanente en salud. Las prácticas pedagógicas deben basarse en un aprendizaje significativo, de modo que los sujetos sean responsables de su proceso de trabajo y de una reflexión crítica sobre trabajo diario.

Descriptores: Trabajo, Atención primaria de salud, Educación Continua.

\section{INTRODUÇÃO}

A Estratégia Saúde da Família (ESF) tem organizado e ampliado as ações da Atenção Primária à Saúde (APS) nas últimas décadas, seguindo os preceitos do Sistema Único de Saúde (SUS) (VIDAL, et al., 2016).

Considerando a portaria $\mathrm{n}^{\circ} 2.436$, de 21 de setembro de 2017, a APS é contemplada como uma inovação tecnológica não material de maior impacto político-social nos determinantes e condicionantes da saúde, pois aperfeiçoou o processo de trabalho transformando a forma do pensar e do fazer saúde, sendo destacada por seus princípios teóricos e políticos, oferecendo uma prospectiva para romper o paradigma tradicional da saúde biomédica (SORATTO et al., 2015; BRASIL, 2017).

O Agente Comunitário de Saúde (ACS) tem como importante característica ser profissional e morador da comunidade em que atua. Marcado por um trabalho que abarca o acolhimento, vínculo e cuidado, ele guia o caminho a ser percorrido pela equipe de saúde para promover um cuidado longitudinal aos usuários, por meio das visitas domiciliares, ações e o convívio junto à comunidade
(VIDAL, et al., 2016; ANDRADE; CARDOSO, 2017).

O seu processo de trabalho se relaciona com a nova concepção do modelo de atenção à saúde, dispondo de um olhar ampliado sobre o indivíduo, a família e a comunidade na perspectiva biopsicossocial, por proporcionar a relação entre o usuário e a Unidade de Saúde. Sua atuação contribui efetivamente no planejamento e intervenções em saúde, pois o ACS convive com a realidade da comunidade local, podendo assim está mais próximo da população e das problemáticas que a atinge, o que possibilita promover uma orientação coerente às famílias, ações educativas e acompanhamento de programas. Entretanto é notório o sentimento de desvalorização que os ACS possuem, quando relacionado à falta de reconhecimento e incentivo de seu trabalho pela gestão e comunidade, quando comparado a outros profissionais com formação superior (GUANAES-LORENZI; PINHEIRO, 2016a).

Além disso, outra fragilidade no processo de trabalho deste trabalhador é que as ações educacionais voltadas para os ACS têm sido baseadas em 
capacitações e treinamentos pontuais, sem considerar o contexto que atuam e suas subjetividades (PEREIRA et al., 2016).

Nesse sentido, a Educação Permanente em Saúde (EPS) contribui efetivamente, pois proporciona uma estratégia de construção coletiva, por meio do diálogo e da reflexão, transformando a prática técnica diária; de pacto para reorganizar a gestão do trabalho, a atenção e o controle social, uma vez que se procura levantar soluções em conjunto para problemáticas encontradas nas ações cotidianas. Com ela os trabalhadores discutem casos, ações e intervenções, a fim de promover a resolutividade e qualidade do serviço, mudando o processo de trabalho e sua organização uma vez que considera as necessidades de saúde do usuário e comunidade. (ROSSETTI et al., 2019).

A Política Nacional de Educação Permanente em Saúde (PNEPS) visa que a mudança nos serviços, no ensino e na condução do sistema de saúde, não pode ser considerada apenas uma questão técnica. Envolve alterações nas relações, nos processos, nos atos de saúde e nas pessoas (BRASIL, 2018).

A partir de tais reflexões os seguintes questionamentos são concebidos: Como ocorre o processo de trabalho dos ACS? Quais fatores facilitam e dificultam o seu processo de trabalho? Qual a perspectiva dos ACS em relação à EPS? Com essas questões norteadoras a sensibilidade é instigada para o reconhecimento das individualidades da realidade a qual o ACS está inserido, promovendo assim a reflexão-crítica dos ACS a respeito do seu processo de trabalho e ações de saúde. Com isso, o presente estudo tem por objetivo discutir o processo de trabalho dos ACS à luz da EPS.

\section{MATERIAIS E MÉTODOS}

Trata-se de uma pesquisa descritiva e exploratória, de abordagem qualitativa, delineada pelo constructo da pesquisa-ação que possuiu como característica importante, o entrosamento entre pesquisador e participante, favorecendo uma transformação efetiva da realidade, melhorando a prática já existente (SILVA et al., 2019).

O cenário do estudo foram três Unidades Básicas de Saúde (UBS) localizadas na cidade de Campina Grande, Paraíba, Brasil. A fim de respeitar os preceitos éticos, as UBS serão aqui identificadas como UBSa, UBSb e UBSc.

A amostra do presente estudo foi composta pelos ACS das cinco equipes das UBS, sendo 06 ACS da UBSa, 06 ACS da UBSb e 04 da UBSc totalizando 16 trabalhadores. A coleta de dados ocorreu por meio de questionário com questões abertas e fechadas que tinha por finalidade levantar o perfil dos ACS; e através de oficinas de trabalho, tendo em vista que elas possibilitam um espaço democrático aos sujeitos para o debate, expressando seus pensamentos e experiências, num ato reflexivo de análise, julgamento e proposição de soluções de maneira coletiva para a construção de conhecimentos e propostas para transformação das práticas em saúde (CHIESA et al., 1995).

Norteadas pelos princípios da EPS, as oficinas tinham como finalidade ampliar a visão dos ACS a respeito das problemáticas que surgiam durante o seu processo de trabalho, assim como sensibiliza-los para a importância da reflexão/ação por meio da ação educativa. A EPS é um processo de aprendizado que visa buscar por soluções criativas para as problemáticas encontradas, incentivando o trabalhador como um sujeito ativo no processo. Esse processo também desenvolve o trabalho em equipe matricial, a melhoria permanente da qualidade do cuidado à saúde e a humanização do atendimento (CECCIM, 2019).

A PNEPS trás como possibilidade a transformação do trabalho do SUS a partir de três fundamentos centrais da EPS: a micropolítica do 
trabalho vivo, método da roda e problematização/aprendizagem significativa. A micropolítica reconhece o espaço do trabalho como potente criador de novas subjetividades essenciais para a mudança institucional; o método da roda permite um espaço de discussão democrático que valoriza a liberdade, ou seja, permite a expressão de desejos, interesses e valores particulares e se articula para a criação de espaços de diálogo; a problematização pode contribuir para educar os sujeitos para assumir um compromisso ético-político e tornar-se capaz de atuar criticamente nos micro espaços da saúde; por fim, a aprendizagem significativa refere-se a uma pedagogia que concebe um papel mais ativo do aluno/trabalhador, que precisa ter disposição para aprender, pois confronta-se com a tradição da memorização do conteúdo como acontece nos modelos tradicionais ou da educação continuada (LEMOS, 2016).

O planejamento das oficinas foi de acordo com as necessidades de aprendizagem dos ACS, sendo ao todo 32 oficinas de trabalho realizadas. $\mathrm{O}$ planejamento foi efetivado em dois momentos distintos: no período de setembro de 2015 a abril de 2016 foram feitas 12 oficinas de trabalho na UBSa com 06 ACS, no período de setembro de 2016 a março de 2017, foram efetuadas 12 oficinas de trabalhos com os 06 ACS da UBSb e 08 oficinas de trabalho na UBSc com 04 ACS, no período de outubro de 2017 a abril de 2018.

As ações aconteceram nas salas de reuniões das respectivas UBS, com duração máxima de 2 horas. Nos encontros se fizeram presentes os sujeitos do estudo, um moderador, um relator e um auxiliador.

As discussões das oficinas foram gravadas e os dados transcritos na íntegra para posterior análise e tratamento dos conteúdos, sendo os sujeitos da pesquisa denominados por tipos de pedras preciosas para preservar o anonimato dos participantes. Para a análise dos dados utilizou-se a técnica de análise de conteúdo proposta por Bardin, composta por quatro etapas operacionais, sendo estas: organização da análise, codificação, categorização e inferência (BARDIN, 2018).

As normas preconizadas pela Resolução $n^{\circ}$ 466/12 do Conselho Nacional de Saúde (CNS) foram respeitadas. Aos sujeitos desta pesquisa foi ofertada e realizada a leitura do Termo de Consentimento Livre e Esclarecido (TCLE), o qual constou informações sobre o estudo, o compromisso de preservação da identidade das participantes por parte dos pesquisadores e solicitou-se a autorização para gravar as oficinas. Essa pesquisa foi aprovada no comitê de ética do Hospital Universitário Alcides CarneiroHUAC, CAAE 11893112.0.0000.5182.

\section{RESULTADOS E DISCUSSÃO}

No quadro 1 as respostas dos questionários que levantou o perfil dos ACS estão agrupadas para melhor visualização.

A maioria dos ACS é do sexo feminino $(93,7 \%)$, estão na faixa etária com mais de 50 anos $(31,2 \%)$, possuem mais de 20 anos de atuação na UBS $(37,5 \%)$ e têm o ensino médio completo $(93,7 \%)$. Quanto ao número de capacitações, este teve uma variação considerável (um à sete), estando a maioria com três $(33,3 \%)$.

Foram efetivadas 32 oficinas de trabalho com os ACS das UBSa, UBSb e UBSc. Cabe ressaltar que os ACS optaram por temáticas que eram recorrentes no seu cotidiano de trabalho e, principalmente, escolheram aquelas que predominavam o sentimento de insegurança e fragilidade do conhecimento no grupo.

O quadro 2 evidencia a atividade realizada, temática e data correspondente, em cada cenário. 
Quadro 1. Caracterização dos agentes comunitários de saúde participantes da pesquisa da UBSa,

UBSb e UBSc de Campina Grande, Paraíba, Brasil, 2018.

\begin{tabular}{|c|c|c|c|c|c|}
\hline SUJEITOS & SEXO & FAIXA ETÁRIA & TEMPO DE ATUAÇÃO & ESCOLARIDADE & CAPACITAÇÃO (n) \\
\hline Topázio & Feminino & 31 a 35 anos & Menos de 1 ano & Ensino Médio Completo & 1 \\
\hline Alexandrita & Masculino & 31 a 35 anos & De 11 a 15 anos & Ensino Médio Completo & 3 \\
\hline Turmalina & Feminino & 31 a 35 anos & De 11 a 15 anos & Ensino Médio Completo & 3 \\
\hline Água Marinha & Feminino & 31 a 35 anos & De 11 a 15 anos & Ensino Médio Completo & 3 \\
\hline Opala & Feminino & 31 a 35 anos & De 11 a 15 anos & Ensino Médio Completo & 4 \\
\hline Âmbar & Feminino & 35 a 40 anos & Mais de 20 anos & Ensino Superior Incompleto & 7 \\
\hline Ametista & Feminino & 46 a 50 anos & Mais de 20 anos & Ensino Médio Completo & 4 \\
\hline Safira & Feminino & Mais de 50 anos & Mais de 20 anos & Ensino Médio Incompleto & 3 \\
\hline Diamante & Feminino & 40 a 45 anos & De 11 a 15 anos & Ensino Médio Completo & 2 \\
\hline Turquesa & Feminina & 46 a 50 anos & Mais de 20 anos & Ensino Médio Completo & 1 \\
\hline Esmeralda & Feminino & 40 a 45 anos & 16 a 20 anos & Ensino Médio Completo & 2 \\
\hline Rubi & Feminino & 36 a 40 anos & 16 a 20 anos & Ensino Médio Completo & 2 \\
\hline Jade & Feminino & Mais de 50 anos & 16 a 20 anos & Ensino Médio Completo & 6 \\
\hline Citrino & Feminino & Mais de 50 anos & 16 a 20 anos & Ensino Médio Completo & 3 \\
\hline Aquamarine & Feminino & Mais de 50 anos & Mais de 20 anos & Ensino Médio Completo & 7 \\
\hline Pérola & Feminino & Mais de 50 anos & Mais de 20 anos & Ensino Médio Completo & 3 \\
\hline
\end{tabular}

Fonte: Dados da pesquisa, 2016-2018.

Quadro 2. Explanação das oficinas de trabalho realizadas com os agentes comunitários de saúde das

UBSa, UBSb e UBSc de Campina Grande, Paraíba, Brasil, 2018.

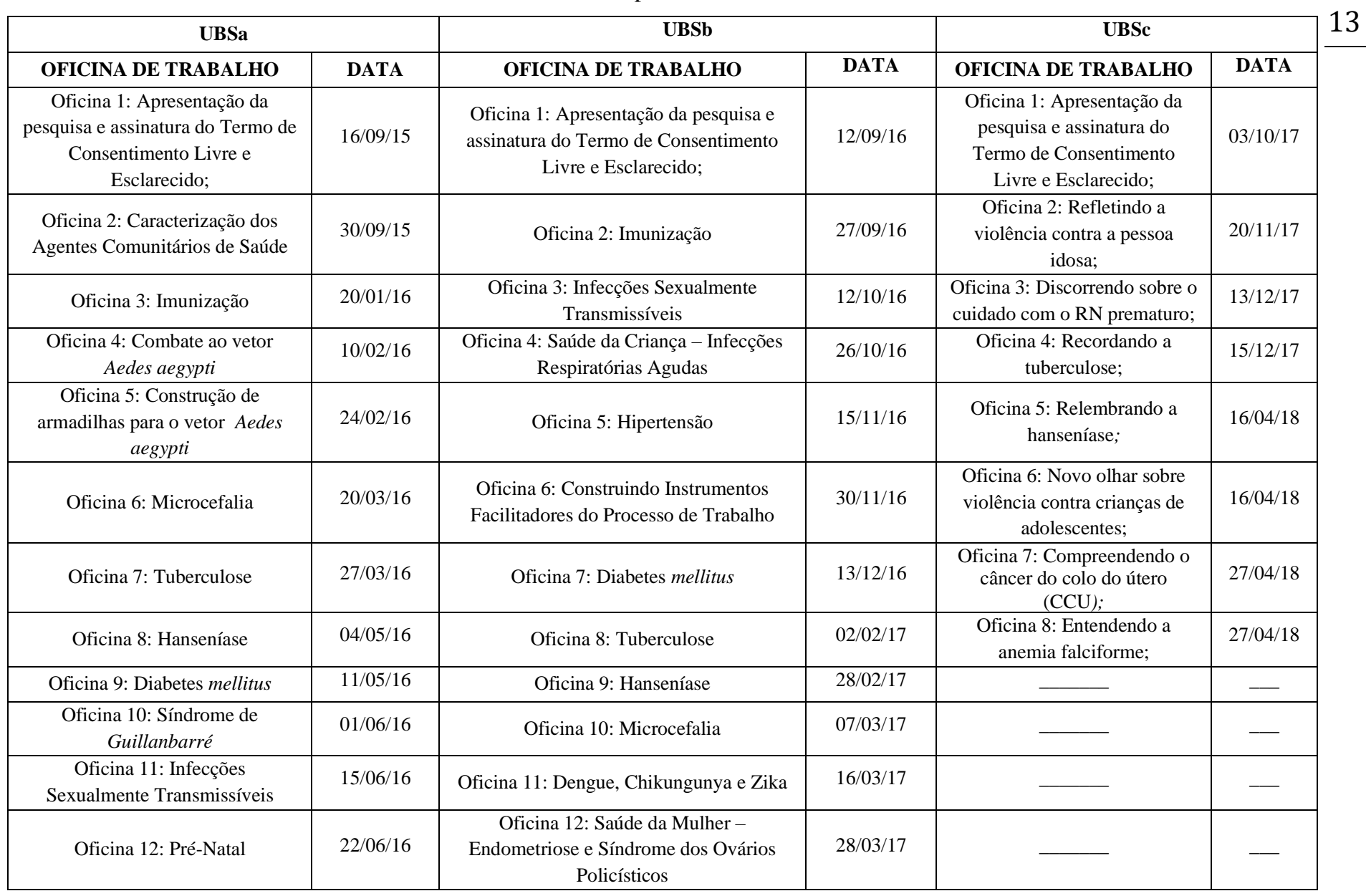

Fonte: Dados da pesquisa, 2016-2018. 
A análise de discussão exprimiu as seguintes categorias discutidas a seguir: CATEGORIA 1: FACILIDADES E DIFICULDADES NO DIA A DIA DE TRABALHO; CATEGORIA 2: AS POTENCIALIDADES DO PROCESSO DE TRABALHO DO AGENTE COMUNITÁRIO DE SAÚDE; CATEGORIA 3: PERSPECTIVA DOS AGENTES COM A EDUCAÇÃO PERMANENTE EM SAÚDE

\section{Facilidades e dificuldades no dia a dia de trabalho}

O trabalho do ACS é revestido de complexidade, uma vez que ele está em constante interação com a comunidade. Ao adentrar os domicílios e obter maior proximidade com os usuários, há uma maior disponibilidade para escutar as queixas, fazendo com que o ACS se comprometam diretamente com a necessidade de dar respostas e encaminhamentos aos problemas encontrados. Ao mesmo tempo, deve compartilhar com a equipe e agir de acordo com as possibilidades e limites dela mesmo e do SUS (SAMUDIO et al., 2017). Frente às reflexões sobre seu processo de trabalho, os ACS discutiram sobre os desafios para o desempenho de suas atividades, apontando as seguintes fragilidades:

\footnotetext{
"Burocracia pra resolver coisas simples e falta de insumos" (Rubi).

"Falta o envolvimento da equipe como um todo, o comprometimento da gestão e a falta de subsídios." (Turquesa).

"Dificuldade em casos de doenças desconhecidas.” (Topázio).

“Falta de capacitação para os ACS.” (Jade).
}

Os ACS reconhecem como fragilidade o excesso de procedimentos burocráticos que eles ficam responsáveis, fazendo com que eles passem mais tempo na UBS do que no próprio território, ocupando atividades que não são do seu encargo. Com isso, eles ficam responsáveis por problemáticas relacionadas à rede de saúde que não estão ao seu alcance de resolução, acarretando na culpabilização. Existe ainda uma comunicação fragilizada entre profissionais de nível superior e ACS, interferindo diretamente nos cuidados com os usuários, reduzindo a confiança da comunidade para com o ACS. É observado o despreparo da equipe frente a doenças que não estão na rotina do território, evidenciando a ausência de capacitações para a equipe como um todo, e o preparo fragilizado desses profissionais em atuarem de acordo com os protocolos e manuais do ministério da saúde.

Para os ACS, esses fatos colaboram para o não desenvolvimento e/ou descontinuidade do seu trabalho, acarretando na diminuição da sua valorização profissional. A valorização do seu trabalho sentida pela comunidade depende da sua capacidade como trabalhador de solucionar os problemas apresentados pelos usuários, ou seja, é uma credibilidade dinâmica, o que é potencialmente estressante (GUANAES-LORENZI; PINHEIRO, 2016b). Ele é um trabalhador facilitador do acesso do usuário ao serviço, como também pode ser o responsável pela ausência da efetivação desse direito, pois quando um usuário se depara com dificuldades de acesso após um encaminhamento do ACS, o sentimento de confiança por toda a equipe é reduzida (PICCININI; SILVA, 2015).

O fator limitante de destaque foi a falta de capacitações direcionadas a esses trabalhadores. O ACS tem um papel singular, haja vista, o vínculo que possui com a comunidade. Porém, em sua maioria, eles podem ter seu conhecimento limitado pela insuficiência de capacitação, o que pode ser um fator restringente na conscientização da população atendida por ele. Diversas dúvidas se fizeram 
presentes, com destaque para as temáticas da tuberculose, hanseníase, hipertensão, diabetes, cuidados em saúde da mulher e, principalmente, imunização, já que constantemente o calendário vacinal está se modificando.

"Tinha coisa que a gente achava que sabia, mas sabia errado, e muita coisa mиdou... Muda muito e a gente fica meio confusa." (Rubi).

"A gente sabe orientar uma pessoa pra vir na unidade de saúde pra pedir os exames, mas pra gente dizer assim, o que é tuberculose $e$ tuberculose é isso, não. Porque a gente nunca teve treinamento sobre isso, nem de hanseníase." (Copo de Leite).

Estudos afirmam a relevância do ACS como o profissional que orienta a comunidade de acordo com as informações adquiridas com a equipe, dialogando e aproximando as famílias dos serviços de saúde. Destacando sua atuação como facilitador, dada à possibilidade de adentrar na intimidade dos usuários, percebendo suas necessidades individuais e coletivas, destacando-se a atuação com redes de relacionamentos significativos, como família, amizade, trabalho e comunidade (SAMUDIO et al., 2017).

Dessa forma ACS é um dos trabalhadores mais proativos na execução de ações que visam à prevenção, promoção, vigilância, detecção precoce e busca ativa, contudo, a falta de capacitação e o apoio fragilizado da equipe limitam a sua atuação e conscientização do usuário, não alcançando o que é considerado ideal e resolutivo (LEITE et al., 2015; SOUZA, 2015; SOUSA et al, 2017).

Estudos afirmam que os ACS participam do processo de trabalho de maneira instrumental, não dispondo de ferramentas necessárias para a resolução de diferentes situações que ocorrem em seu dia a dia de trabalho, basicamente reproduzindo orientações de conduta aos moradores atuando muitas vezes segundo o senso comum. Somando-se com a comunicação interprofissional fragilizada, pode-se acarretar em um agir sem embasamento teórico (CORDEIRO; SOARES, 2015).

Outra limitação levantada foram os casos de usuários analfabetos e usuários de drogas presentes na comunidade.

"Porque a maioria do povo da minha área é analfabeto." (Safira).

"Eu tenho dificuldade porque o pessoal da minha área não sabe ler.” (Gérbera).

“(...) tô trabalhando em uma área onde tem a invasão, e lá eu encontro crianças armadas, vejo ai a gente se sente insegura, sabe que a comunidade tá insegura, e a gente não tem muito o que fazer. Porque eu fui fazer uma abordagem a três adolescentes sobre a droga e um mais adulto chegou a mim e disse cuidado tia que as vezes não sabe nem porque amanhece com a boca cheia de formiga, quer dizer e isso ai eu tomei como uma ameaça(...)." (Pérola).

"a nossa comunidade tem muitos jovens, no vício de bebidas, de drogas, e a gente precisa assim de uma assistência maior da gestão, os conselhos tutelares nos ajudar mais para solucionar os problemas que a gente identifica, e comunica, mas a gente não tem no caso a contrareferência, a resposta, a resolutividade daquela situação que a gente, nossa obrigação nosso trabalho é identificar o problema, mas às vezes a gente identifica o problema, mas não vê solução" (Jade).

Essa barreira influencia negativamente na adesão terapêutica já que grande parte dos usuários ingere mais de duas drogas por dia em horários diferentes, dificultando a identificação de qual medicamento tomar em cada horário.

Há uma grande dificuldade quando se trata de como abordar os usuários de drogas, foi relatada a complexidade de tratar desses assuntos com a comunidade complicando dessa forma a realização de ações pelo o ACS, até mesmo quando se diz respeito às visitas domiciliares. De acordo com Batista e Souto (2017), persiste um conflito entre uma cultura leiga e a ciência na percepção de ACSs sobre essas 
pessoas e o processo o qual estão inseridos. Esse conflito prejudica a integralidade do cuidado por dificultar a participação qualificada dos ACSs na assistência.

Foi citada a fragilidade referente à falta de segurança sentida por esses profissionais, corroborando com pesquisas que abordam agressividade e violência por parte de usuários de drogas de forma que o ACS diminua as visitas domiciliares naquela área, pelo sentimento de medo do contato com estas pessoas, sob a justificativa de se resguardarem de um possível mal que estes poderiam lhe causar (MELO et al., 2016). Dessa maneira, é imprescindível que os profissionais sejam capacitados para formular estratégias que respondam as necessidades e dificuldades apresentadas pelos usuários.

A APS deve refletir o modelo de assistência que priorize o indivíduo em sua subjetividade através do trabalho em equipe e olhar holístico, realizando suas atividades para além da UBS, atingindo usuário, família, comunidade e território (VIEIRA; FERREIRA, 2015).

\section{As potencialidades do processo de trabalho do agente comunitário de saúde}

As potencialidades do processo de trabalho do ACS na APS são peças fundamentais no envolvimento da população para o enfrentamento dos problemas de saúde, principalmente na modificação das condições de vida que prejudicam os benefícios da saúde, esse profissional está presente no acolhimento, vínculo e na humanização das práticas, o que resulta no sucesso das ações e acompanhamento dos usuários (RAIMUNDI et al., 2016).Quando questionadas sobre as suas atribuições os ACS responderam:

"Visitas domiciliares, encaminhamento da comunidade à unidade." (Safira)
"Somos responsáveis por várias atividades como grupos educativos, visitas domiciliares e auxílios dentro do posto[UBS]."(Jaspe)

"Visitas domiciliares, acompanhamento de gestantes, crianças, hipertensos, diabéticos $e$ outros”. (Topázio)

$\mathrm{O}$ ACS, por ser o elo entre a equipe e a comunidade realiza as visitas domiciliares, cadastro, identificação de famílias vulneráveis, comunicação com a equipe, orientação sobre o uso dos serviços de saúde, realização de encaminhamentos, promoção de educação em saúde e participação da reflexão do trabalho em equipe (NASCIMENTO et al., 2017).

Mesmo com todas as dificuldades presentes em seu dia a dia, os ACS afirmam gostar do seu ofício, e reconhecem sua profissão como essencial para manutenção e recuperação da saúde dos usuários; isso porque, conhecem como nenhum outro profissional, a realidade da sua comunidade. A fala a seguir destaca a importância e o reconhecimento da atuação do ACS na comunidade da UBS em questão:

"Antes dos ACS começarem esse trabalho, morria muita criança do bairro. Quando os agentes começaram a atuar aqui houve uma redução visivel, então assim, o trabalho dos ACS aqui no bairro foi muito eficaz." (Turquesa).

As visitas domiciliares foram destaque nas oficinas, onde elas demonstraram sentimentos de felicidade por ter um relacionamento próximo com os usuários. Em contrapartida, Bezerra e Feitosa (2018) evidenciaram em estudo realizado em Quixadá-CE, que os ACS apresentaram dificuldades no acesso às famílias, o que gerava sentimentos de tristeza e angústia. Observou-se que a maioria dos ACS possuíam pouco tempo de atuação (dois anos), e que a inserção na comunidade é um processo de construção para que o vínculo seja efetivado.

O envolvimento e o comprometimento com as famílias atendidas em um longo período foram 
colocados como estratégia para formação de vínculo, aspecto que os ACS consideram ser primordial para execução do seu trabalho, pois no momento em que têm acesso a intimidade dos seus usuários eles podem identificar problemas e sugerir soluções. Como a maioria dos ACS possuía um tempo de atuação considerável (11-15 anos), a formação do vínculo está bem empregada sendo constituinte da sua força de trabalho, como pode ser visto:

"A força de trabalho e compromisso com o trabalho comunitário." (Turmalina)

“Vínculo do ACS com a comunidade.” (Safira).

“O envolvimento com a comunidade.” (Rubi).

A relação afetiva e o vínculo entre ACS e família favorecem o envolvimento dos usuários no seu plano de cuidados e a participação efetiva no trabalho da equipe, contribuindo para a transformação social (BEZERRA; FEITOSA, 2018).

Frente às problemáticas do dia a dia, os trabalhadores buscam por resoluções. Nesse sentido, elas reafirmam sua importância como agente educador e vigilante do cuidado e destacam estratégias usadas no seu dia a dia:

"Quando alguém vai casar eu digo assim_vamos fazer os exames juntos? Vamos iniciar a vida de casado juntos?_ porque ali já adquire aquela rotina dos dois fazerem." (Rubi).

"Eu incentivei uma turma da minha área. Eu disse _sabe como é que você consegue fazer o exame super rápido?!_ Sendo doador de sangue." (Rubi).

"Quando eu quero que os meus hipertensos passem pelo exame de rotina, eu falo com a enfermeira, e agendo pra eles virem passar por ela pra fazer o acompanhamento e pedir todos os exames de rotina, porque se a gente for esperar pra formar em questão de grupo que nem antes, não tem, então assim pra não ficar solto, eu vou combinando com a enfermeira." (Diamante).
Portanto, em distintas ocasiões elas aproveitam o momento para instruir os indivíduos à realizarem exames de rotina. $\mathrm{O}$ incentivo a realização dos exames é extremamente necessário, haja vista que quanto mais cedo for diagnosticada alguma infecção, mais rápido se inicia o tratamento, evitando ou amenizando os seus agravos.

Com relação à adesão terapêutica na comunidade com muitos usuários analfabetos, os ACS ressaltaram o cuidado de perto com este usuário:

\footnotetext{
"Uma pessoa da minha área veio pegar o remédio, só que ela é analfabeta e toda vez que ela pega o remédio, tem por obrigação ir lá em casa, porque eu separo pra ela ver qual é o remédio." (Safira).
}

A pesquisa de Albuquerque (2016) realizada com os usuários do município de Colombo-PA, identificou que de um total de 63 usuários, 30 eram analfabetos e 33 alfabetizados. Dentre os analfabetos, $40 \%$ dos usuários não aderiam ao tratamento recomendado. Isso ocorre devido ao seu conhecimento fragilizado sobre a doença. Como importantes fontes de apoio para garantir a adesão medicamentosa estão a família e, em seguida, a equipe da UBS.

\section{Perspectiva dos agentes com a educação permanente em saúde}

Dentre as várias etapas de um processo educativo, a análise e a avaliação final de cada ciclo são primordiais para o conhecimento do impacto produzido na concepção e ações dos partícipes. A avaliação serve para identificar os pontos fortes e frágeis de um processo educativo e, a partir desse resultado, rever a eficácia da metodologia pedagógica. Dessa forma busca-se o aprimoramento das ações com o intuito de influenciar de maneira 
positiva os processos de trabalho em saúde (SILVA et al., 2016).

Os ACS fizeram uma avaliação sobre as oficinas realizadas e a importância da EPS como instrumento orientador do seu processo de trabalho:

\begin{abstract}
"Acho assim, que o ACS, ele sempre tem que tá se reciclando. Porque se ele vive em educação assim... orientando a comunidade, ele tem que ser reciclado. Isso influencia no seu modo de trabalhar." (Esmeralda).

"E as vezes o usuário deixa de se cuidar por falta de uma informação que eu, como profissional, não soube passar pra ele. Então é muito importante esses encontros, essas formações, porque cada vez mais a gente vai ganhando experiência e ajudando a comunidade a prevenir, a se cuidar, então é muito bom!" (Ametista).
\end{abstract}

A mesma perspectiva é contemplada na análise dos participantes do estudo de Peres, Silva e Barba (2016) realizado em São Carlos-SP, onde a EPS foi reconhecida como uma potencial estratégia que influi positivamente no processo de trabalho e, consequentemente, nos serviços de saúde.

Em consonância a pesquisa que destaca a EPS como primordial instrumento na atualização de conhecimentos, pois através dela dúvidas são esclarecidas e os saberes são renovados (COELHO et al., 2018).

Não obstante, as ACS acolheram essa perspectiva educativa, colocando-se como protagonistas na partilha e desenvolvimento de saberes: escutaram, discutiram, propuseram e construíram. Para promover o aprendizado, é necessário o estímulo ao desenvolvimento de habilidades, como o pensamento crítico e reflexivo. Dessa forma os sujeitos se tornam capazes de solucionar problemas e desempenhar papéis conscientes na sociedade (COTTA et al., 2015).

\section{CONCLUSÃO}

Por ser um profissional com um potencial transformador haja vista o seu contexto histórico diante das perceptíveis mudanças na atenção à saúde, pode-se perceber que o ACS tem sido objeto de muitas pesquisas, principalmente no que condiz aos desafios decorrentes do seu processo de trabalho, avaliação e levantamento das ações desenvolvidas por esses trabalhadores sob a ótica de um tema específico e a influência da educação no seu processo de trabalho. Contudo, poucos estudos desempenharam intervenções que pudessem promover ressignificações do processo de trabalho do ACS.

Além de conhecer a realidade vivenciada pelo ACS e identificar potencialidades e fragilidades do seu processo de trabalho, esse estudo se estabeleceu por uma proposta interventiva, que promoveu um novo olhar do ACS frente a sua práxis.

Por meio das discussões coletivas e das análises das situações vivenciadas em seu cotidiano de trabalho, identificou-se que a inserção da EPS na realidade profissional dos ACS fez com que eles percebessem a necessidade do seu constante processo de formação, promovendo um indicativo de mudança nas suas práticas cotidianas.

A constante problematização conduziu os ACS a compreender que, além do conhecimento, está presente a sua capacidade de identificar fragilidades em sua comunidade, podendo assim planejar e sugerir soluções aos seus usuários e a equipe de saúde.

As seguintes dificuldades se fizeram presentes para a realização do estudo: a greve municipal dos servidores da saúde, que aconteceu no início das oficinas e fragilizou o vínculo por determinado tempo; a resistência por parte de alguns ACS em participar da pesquisa e, por fim, a comunicação e envolvimento entre os membros das equipes fragilizado. 
Portanto sugerimos o tema para futuros estudos que intervenham sobre essa realidade, a fim de consolidar e ampliar os avanços provenientes desse estudo, além de vislumbrar esta proposta como instrumento que pode se tornar referência para o desenvolvimento de novos estudos sobre a temática a partir de outras perspectivas.

Reafirma-se o papel do ACS como agente educador, logo, sua constante capacitação é em suma, indispensável na formação de um trabalhador reflexivo e pensante. Portanto, as práticas pedagógicas devem sempre ser baseadas na aprendizagem significativa, para que haja a responsabilização dos sujeitos frente ao seu processo de trabalho.

Destaca-se que apesar da evolução nas formas de enxergar e executar seu trabalho, é necessária a manutenção da EPS como instrumento de aperfeiçoamento e mudanças. Para tanto a pactuação e o constante diálogo entre academia, unidade de saúde e gestão se faz necessária para o fortalecimento dos processos educativos com vistas a uma melhor assistência a saúde dos usuários do SUS.

Todos os autores declararam não haver qualquer potencial conflito de interesses referente a este artigo.

\section{REFERÊNCIAS}

ALBUQUERQUE, G. S. C.; NASCIMENTO, B.; GRACIA, D.F.K.; PREISLER, L.; PERNA, P. O.; SOUZA E SILVA, M. J. Adesão de hipertensos e diabéticos analfabetos ao uso de medicamento a partir da prescrição pictográfica, Trab. Educ. Saúde, v. 14, n. 2, p. 611-24, 2016. Disponível em: <http://www.scielo.br/pdf/tes/v14n2/1678-1007-tes1981-7746-sip00112.pdf>. Acesso em 21 nov. 2017.

ANDRADE, V. M. P.; CARDOSO, C. L. Visitas domiciliares de agentes comunitários de saúde: concepções de profissionais e usuários, Psico-USF, Bragança Paulista, v. 22, n. 1, p. 87-98, jan./abr., 2017. Disponível em: < http://dx.doi.org/10.1590/1413-82712017220108>. Acesso em 18 jul. 2017.
BARDIN, L. Análise de conteúdo. Tradução de Luís Antero Reto e Augusto Pinheiro. São Paulo: Edições 70, 2018.

BATISTA, K; SOUTO, B.G.A. Visão de agentes de saúde sobre usuários de drogas. ABCS Health Sci. 2017; v. 42 n.3 p.129-136. Disponível em: < www.portalnepas.org.br $>$ abcshs $>$ article $>$. Acesso em : 01 abr 2020.

BEZERRA, Y. R. N.; FEITOSA, M. Z. S. A afetividade do agente comunitário de saúde no território: um estudo com os mapas afetivos, Cienc. saúde colet., v. 23, n. 3, p. 813-822, 2018. Disponível em: <https://www.scielosp.org/scielo.php?script=sci_artte $\mathrm{xt} \& \mathrm{pid}=\mathrm{S} 1413-$

81232018000300813\#ModalArticles>. Acesso em 08 jul. 2018.

BRASIL. Ministério da Saúde. Gabinete do Ministro. Portaria $n^{0}$ 2.436, de 21 de setembro de 2017. Aprova a Política Nacional de Atenção Básica, estabelecendo a revisão de diretrizes para a organização da Atenção Básica, no âmbito do Sistema Único de Saúde (SUS). Disponível em: < http://bvsms.saude.gov.br/bvs/saudelegis/gm/2017/prt 2436_22_09_2017.html >. Acesso em 30 jun. 2018.

BRASIL. Ministério da Saúde. Secretaria de Gestão do Trabalho e da Educação na Saúde. Departamento de Gestão da Educação na Saúde. Política Nacional de Educação Permanente em Saúde: o que se tem produzido para o seu fortalecimento? / Ministério da Saúde, Secretaria de Gestão do Trabalho e da Educação na Saúde, Departamento de Gestão da Educação na Saúde - 1. ed. rev. - Brasília : Ministério da Saúde, 2018.

CECCIM, R. B. Emergência de um "campo de ação estratégica": ordenamento da formação e educação permanente em saúde, SANARE, v. 18, n. 1, p. 6880, 2019. Disponível em: <https://sanare.emnuvens.com.br/sanare/article/view/ 1307/688>. Acesso em 12 jun 2019.

CHIESA, A.M, WESTPHAL, M.F. A sistematização de oficinas educativas problematizadoras no contexto dos serviços de saúde. Saúde em Debate, n.45, p.1922, 1995.

COELHO, J. G, VASCONCELLOS, L. C. F, DIAS, E. C. A formação de agentes comunitários de saúde: construção a partir do encontro dos sujeitos. Trab. Educ. Saúde, Rio de Janeiro, v. 16 n. 2, p. 583-604, maio/ago. 2018. Disponível em: <http://www.scielo.br/pdf/tes/v16n2/1678-1007-tes1981-7746-sol00113.pdf> Acesso em: 09 jan 2020.

CORDEIRO, L.; SOARES, C.B. Processo de trabalho na Atenção Primária em Saúde: pesquisaação com Agentes Comunitários de Saúde. Ciênc. saúde coletiva, Rio de Janeiro, v. 20, n. 11, p. 
3581-3588, Nov. 2015 . Disponível em: $<$ http://www.scielo.br/scielo.php?script=sci_arttext\& pid=S1413-

81232015001103581\&lng=en\&nrm=iso >. Acesso em: 01 Abr. 2020.

COTTA, R. M. M.; COSTA, G. D.; MENDONÇA, E. T. Portfólios crítico-reflexivos: uma proposta pedagógica centrada nas competências cognitivas e metacognitivas. Interface (Botucatu), v. 19, n. 54, p. 573-588, 2015. Disponível em: <http://www.scielo.br/scielo.php?pid=S141432832015000300573\&script=sci_abstract\&tlng=pt $>$. Acesso em 21 jul. 2017.

GUANAES-LORENZI, C.; PINHEIRO, R. L. Is the value of community healthcare agents in Brazil's family health strategy receiving full recognition? Ciênc Saúde Coletiva [Internet]. 2016 [cited 2017 May 06];21(8):2537-46. Available from: http://www.scielo.br/pdf/csc/v21n8/en_1413-8123csc-21-08-2537.pdf

GUANAES-LORENZI, C.; PINHEIRO, R. L. A (des)valorização do agente comunitário de saúde na Estratégia Saúde da Família. Ciênc. saúde coletiva, Rio de Janeiro , v. 21, n. 8, p. 2537-2546, Aug. $2016 . \quad$ Disponível em: $<$ http://www.scielo.br/scielo.php?script=sci_arttext\& pid=S1413-

$81232016000802537 \& \ln \mathrm{g}=\mathrm{en} \& \mathrm{nrm}=\mathrm{iso}>$. Acesso em: 30 Mar. 2020.

LEITE, M. T.; PAI，S. D.; QUINTANA，J. M.; COSTA, M. C. Doenças crônicas não transmissíveis em idosos: saberes e ações de agentes comunitários de saúde, J. res.: fundam. care. online, v. 7, n. 2, p. 2263-76, abr./jun., 2015. Disponível em: < http://www.seer.unirio.br/index.php/cuidadofundame ntal/article/view/3597/pdf_1531>. Acesso em: 06 jun. 2017.

LEMOS, C. L. S. Educação Permanente em Saúde no Brasil: educação ou gerenciamento permanente?, Cienc saúde colet [online], v. 21, n. 3, pp. 913-922, mar, 2016. Disponível em: $<$ https://doi.org/10.1590/141381232015213.08182015>. Acesso em 12 jun 2019.

MELO, B.C.A; ASSUNÇÃO, J.I.V; VECCHIA, M.D. Percepções do cuidado aos usuários de drogas por Agentes Comunitários de Saúde. Psicol. pesq., Juiz de Fora , v. 10, n. 2, p. 57-66, dez. 2016. Disponível em: <http://pepsic.bvsalud.org/scielo.php?script=sci_artte xt\&pid=S1982-

$12472016000200008 \& \operatorname{lng}=$ pt\&nrm=iso $>. \quad$ Acesso em: 01 abr 2020.
NASCIMENTO, V.F; TERÇAS, A.C.P; HATTORI, T.Y; CABRAL, J.F; GLERIANO, J.S; BORGES, A.P; RIBEIRO, G.R.M.S; SILVA, R.G.M. Percepção de agentes comunitários de saúde sobre visita domiciliária após aperfeiçoamento em saúde da família. Rev. APS. v. 20 n. 3 p. 392 - 402, jul/set. $2017 . \quad$ Disponível em: <https://periodicos.ufjf.br/index.php/aps/article/view/ 15966>. Acesso em: 04 abr. 2020.

PEREIRA, I. D. F.; LOPES, M. R.; NOGUEIRA, M. L.; RUELA, H. C. G. Princípios pedagógicos e relações entre teoria e prática na formação de agentes comunitários de saúde, Trab Educ Saúde, Rio de Janeiro, v. 14, n. 2, p. 377-97, mai./ago., 2016. Disponível em: < http://dx.doi.org/10.1590/19817746-sol00010>. Acesso em 18 jul. 2017.

PERES, C.; SILVA, R. F.; BARBA, P. C. S. D. Desafios e potencialidades do processo de Educação Permanente Em Saúde. Trab. Educ. Saúde, Rio De Janeiro , v. 14, n. 3, p. 783-801, dez. 2016. Disponível em: <http://www.scielo.br/scielo.php?pid=S1981$77462016000300783 \&$ script=sci_abstract $\&$ tlng $=p t>$. Acesso em: 21 jul. 2017.

PICCININI, C.A; SILVA, R.A.N. A ação dos agentes comunitários de saúde e o trabalho vivo em ato. Trab. educ. saúde, Rio de Janeiro, v. 13, n. 2, p. 361-379, Ago. 2015 . Disponível em: <http://www.scielo.br/scielo.php?script=sci_arttext\& pid $=$ S1981 -

$77462015000200361 \& \operatorname{lng}=e n \& n r m=i s o>$ Acesso em: 01 Abr. 2020.

RAIMUNDI, D. M; FERREIRA, F. F; LIMA, F. C. A; SIQUEIRA, V. C. A. Análise de uma Clínica da Família, visão dos enfermeiros do serviço. Rev. esc. enferm. USP, São Paulo, v. 50, n. spe, p. 130-138, June 2016 . Disponível em: $<$ http://www.scielo.br/scielo.php?script=sci_arttext\& pid=S0080-

62342016001100130\&lng=en\&nrm=iso>. Acesso em: 04 Abr. 2020.

ROSSETTI, L.T, SEIXAS, C.T, CASTRO, E.A.B, FRIEDRICH, D.B.C. Educação permanente e gestão em saúde: a concepção dos enfermeiros. Rev Fun Care Online; v. 11, n.1, p: 129-134, jan/mar, 2019. Disponível em: <http://dx.doi.org/10. 9789/21755361.2019.v11i1.129-134.> Acesso em: 02 jun. 2019.

SAMUDIO, J. L. P; BRANT, L. C; MARTINS, A.C.F. D. C; VIEIRA, M. A; SAMPAIO, C. A. Agentes comunitários de saúde na atenção primária no brasil: multiplicidade de atividades e fragilização da formação. Trab. educ. saúde, Rio de Janeiro, v. 15, n. 3, p. 745-769, Dec. 2017 . Disponível em: 
$<$ http://www.scielo.br/scielo.php?script=sci_arttext\& pid=S1981-

$77462017000300745 \& \ln \mathrm{g}=\mathrm{en} \& \mathrm{nrm}=\mathrm{iso}>$. Acesso em: 01 Abr. 2020.

SILVA, L. A. A.; SCHMIDT, S. M. S.; NOAL, H. C.; SIGNOR, E.; GOMES, I. E. M. Avaliação da educação permanente no processo de trabalho em saúde. Trab. Educ. Saúde, Rio De Janeiro , v. 14, n. 3, p. 765-781, dez. 2016. Disponível: $<$ http://www.scielo.br/scielo.php?pid=S1981$77462016000300765 \&$ script=sci_abstract\&tlng=es $>$. Acesso em 21 jul. 2017.

SILVA，O.B.M; BENEDET， D.C.F; LACERDA, M.R; MAFTUM, M.A; BERNARDINO, E; WALL, M.L. Potencialidades, fragilidades e desafios da pesquisa-ação na enfermagem. Rev enferm UFPE on line., Recife, v. 13, n.1, p:227-235, jan., 2019. Disponível em: $<$ https://periodicos.ufpe.br/revistas/revistaenfermage m/article/view/236770/31162 >. Acesso em: 04 abr. 2020.

SORATTO, J.; PIRES, D. E. P.; DORNELLES, S.; LORENZETTI, J. Estratégia saúde da família: uma inovação tecnológica em saúde, Texto Contexto Enfem, Florianópolis, v. 24, n. 2, p. 584-92, abr./jun., 2015. Disponível em: < http://dx.doi.org/10.1590/0104-

$07072015001572014>$. Acesso em 18 jul. 2017.

SOUSA, G. S.; SILVA, R. L. F.; XAVIER, M. B. Hanseníase e Atenção Primária à Saúde: uma avaliação de estrutura do programa. Saúde debate, , v. 41, n. 112, p. 230-242, Mar., 2017 . Disponível em:

$<$ http://www.scielosp.org/scielo.php?script=sci_artte $\mathrm{xt} \& \mathrm{pid}=\mathrm{S} 0103-$

$11042017000100230 \& \operatorname{lng}=e n \& n r m=i s o>$. Acesso em 22 jul. 2017.

SOUZA, G. A. Avaliação das práticas de promoção de saúde voltadas ao controle e prevenção da hipertensão arterial no município de campina grande sob perspectiva dos profissionais da saúde. 2015. 28f. Trabalho de conclusão do curso de fisioterapia. Universidade Estadual Da Paraíba. 2015.

VIDAL, S. V.; GOMES, A. P.; SIQUEIRABATISTA, R. Estratégia saúde da família em cena: a formação bioética dos agentes comunitários de saúde, em três atos, Rev Brasileira Educ Médica, v. 40, n. 1, p. 67-76, 2016. Disponível em: <http://dx.doi.org/10.1590/1981-

52712015v40n1e00842015>. Acesso em 18 jul. 2017.

VIEIRA, M. A.; FERREIRA, M. A. M. Análise do processo de trabalho na estratégia saúde da família em relação à operacionalização dos princípios básicos do SUS. Rev. de Adm. Hospitalar e Inovação em Saúde, v. 12, n. 3, p. 1-9, 2015. Disponível em: <http://revistas.face.ufmg.br/index.php/rahis/article/v 